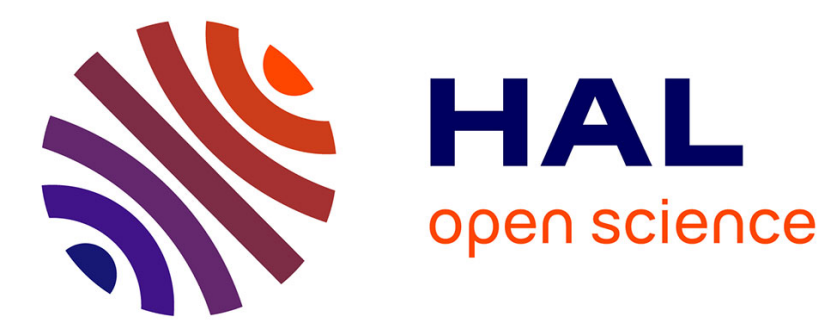

\title{
THEORY OF SURFACE VIBRATIONS IN SUPERLATTICES
}

Bahram Djafari-Rouhani, L. Dobrzynski, O. Hardouin Duparc, R. Camley, A. Maradudin

\section{- To cite this version:}

Bahram Djafari-Rouhani, L. Dobrzynski, O. Hardouin Duparc, R. Camley, A. Maradudin. THEORY OF SURFACE VIBRATIONS IN SUPERLATTICES. Journal de Physique Colloques, 1984, 45 (C5), pp.C5-151-C5-155. 10.1051/jphyscol:1984522 • jpa-00224140

\section{HAL Id: jpa-00224140 https://hal.science/jpa-00224140}

Submitted on 1 Jan 1984

HAL is a multi-disciplinary open access archive for the deposit and dissemination of scientific research documents, whether they are published or not. The documents may come from teaching and research institutions in France or abroad, or from public or private research centers.
L'archive ouverte pluridisciplinaire HAL, est destinée au dépôt et à la diffusion de documents scientifiques de niveau recherche, publiés ou non, émanant des établissements d'enseignement et de recherche français ou étrangers, des laboratoires publics ou privés. 


\section{THEORY OF SURFACE VIBRATIONS IN SUPERLATTICES}

B. Djafari-Rouhani, L. Dobrzynski, O. Hardouin Duparc, R.E. Camley ${ }^{\star}$ and A.A. Maradudin ${ }^{\star}$

Laboratoire d'Etude des Surfaces et Interfaces ${ }^{+}$, Faculté Libre des Sciences et I.S.E.N., 13 me de Toul, 59046 Iille Cedex, France

"Department of Physies, University of Colorado, Colorado springs, CoLorado 80977, U.S.A.

* Department of physics, University of California, Irvine, Califormia 92717 , $U . S . A$.

Résumé - Nous présentons une revue de nos travaux récents sur les vibrations des super-réseaux infinis ou semi-infinis. En utilisant soit la théorie de l'élasticité, soit un modèle atomique simple, nous obtenons des relations explicites pour la dispersion des bandes de volume et des modes de surface.

Abstract - We present a review of our recent theoretical work on the vibrations of an infinite or a semi-infinite superlattice. Explicit expressions are obtained for the dispersion of the bulk bands and of the surface modes, on the basis of elasticity theory or a simple atomic model.

\section{INTRODUCTION}

Despite a great deal of theoretical study on the acoustic waves in layered media[1], there is a renewal of activity in this field with the development of techniques for depositing overlayers on a substrate and fabricating artificial crystals - superlattices (SL). Infrarea $[2,3]$ and Raman $[3,4]$ spectroscopy has been used in semiconductor Sc to obtain the frequencies of the few first folded phonons around the wave vector $\vec{k}=0$ - and very recently their dispersion[5] - as well as the frequencies of phonons in the optical range. on the other hand, Brillouin scattering $[6,4]$ can detect the Rayleigh wave at the surface of a SI. These experiments yield information

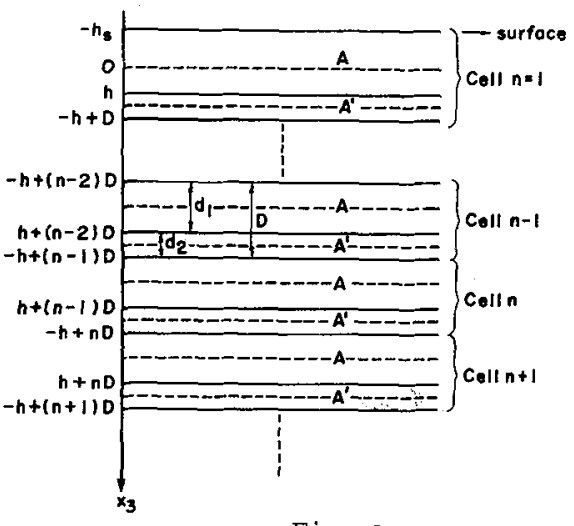

Fig. 1 about the parameters of the films that constitute the sL and their quality.

The surface waves on a SL have also been studied numerical1y $y^{[7,8]}$, showing in particular the possibility of elastic horizontal shear waves [7]. In this paper, we review our recent theoretical work on vibrations in infinite and semi-infinite SL which have the advantage of giving explicit relations governing the dispersion of the modes. In the first part, each film in the sL is treated as an elastic medium characterized by

\footnotetext{
${ }^{+}$Associē au C.N.R.S.
} 
its elastic constants and its density ${ }^{[9-11]}$; the dispersion relations are derived by means of a transfer matrix method. The second part is devoted to a simple atomic model for which the Green's function can be obtained analytically. [12] Further developments will be outlined in each section.

\section{Elastic Model}

The geometry of a semi-infinite superlattice is depicted in Figure 1 . Within the nth unit cell, the equations of motion in the medium $A$, for example, yield the following displacement field

$u_{i}^{(n)}(\vec{x}, t)=\sum_{j=1}^{3}\left[A_{i j}^{(n)} \exp \left(\alpha_{j} x_{3}^{(n)}\right)+B_{i j}^{(n)} \exp \left(-\alpha_{j} x_{3}^{(n)}\right)\right] e^{i\left(\vec{k}_{\|} \cdot \vec{x}_{\|}-\omega t\right)}$.

$\omega$ is the frequency and $\vec{k}_{\|}$the wave vector parallel to the interfaces.

The reduced coordinate $x_{3}^{(n)}=x_{3}-(n-1) D$ is introduced for convenience and ranges from $-h$ to th. The parameters $\alpha_{j}$ are the solutions of a secular determinant of rank 3 while the coefficients $A_{i j}^{(n)}$

(or $B_{i j}^{(n)}$ ) are the eigenvectors of the corresponding matrix. There are consequently six unknown multiplicative constants, let us say

$A_{I j}^{(n)}, B_{I j}^{(n)}(j=1,2,3)$ which have to be determined by using the boundary conditions on the displacements and on the stresses at the different interfaces. By writing these six coefficients as a column vector $\left|\psi_{n}\right\rangle$, the boundary conditions easily give

$$
\left|\psi_{n+1}\right\rangle=\vec{T}\left|\phi_{n}\right\rangle \text {, }
$$

where $\vec{T}$ is a $6 \times 6$ transfer matrix. For an infinite SL, the application of the Bloch theorem in the $x_{3}$-direction, with a wave vector $k_{3}$, gives the eigenvalues as solutions of the determinantal equations

$$
\operatorname{det}\left(\ddot{T}-e^{i k} 3^{D} \vec{I}\right)=0,
$$

where $\vec{I}$ is the $6 \times 6$ unit matrix. For given $\omega$ and $\vec{k}_{\|}$, this equation gives six roots for $k_{3}$, associated two by two, corresponding to propagation in the positive or negative $x_{3}$-direction. In a bulk band these solutions are real while in a gap they have an imaginary part. For a semi-infinite SL, a surface mode has to be sought in the gaps, in the form of a linear combination of three out of the six above solutions, i.e. those corresponding to the attenuation of the wave far from the surface

$$
\begin{gathered}
u_{i}^{(n)}(\vec{x}, t)=\sum_{\mu=1}^{3} R_{\mu} \sum_{j=1}^{3}\left[A_{i j}^{(n)(\mu)}\right. \\
\left.\exp \left(\alpha_{j} x_{3}^{(n)}\right)+B_{i j}^{(n)(\mu)} \exp \left(-\alpha_{j} x_{3}^{(n)}\right)\right] \times \\
x e^{i\left(\vec{k}_{\|} \cdot \vec{x}_{\|}-\omega t\right)}
\end{gathered}
$$


$\mathrm{R}_{\mu}(\mu=1,2,3)$ are arbitrary coefficients introduced to make a linear combination of the three possible solutions. Finally, a surface mode solution must fulfill the vanishing of the stresses at the free surface of the SL. This leads to three linear homogeneous equations in the coefficients $R$, whose determinant has the frequencies of the surface modes as its roots.

The above theory has been applied under the assumption that the media $A$ and $A^{\prime}$ are isotropic, in which case the shear horizontal modes decouple from those polarized in the sagittal plane. The $\vec{T}$ matrix becomes a juxtaposition of a $2 \times 2$ and a $4 \times 4$ matrix. Moreover, we showed[11] that the eigenvalue problem for this last matrix can be solved analytically by introducing the matrix $\vec{M}=\frac{1}{2}\left(\vec{T}+\vec{T}^{-1}\right)$ when the displacements (Eqs. (1) and (4)) are expressed in terms of $\cosh \alpha_{j} x_{3}(n)$ and $\sinh \alpha_{j} x_{3}^{(n)}$ rather than in terms of exponentials. Indeed, the matrix $\vec{M}$ can be block-diagonalized into two $2 \times 2$ submatrices. As an illustration, Fig. 2 gives the shear horizontal bulk bands and surface modes in the case that the two films $A$ and $A$ ' have the same thickness, the same value of $C_{44}$, and a density ratio $\rho$ (AlAs) $/ \rho$ (GaAs) $=0.7$. Fig. 3 presents the sagittal modes of an $A l-W$ superlattice (these are two nearly isotropic media, with very

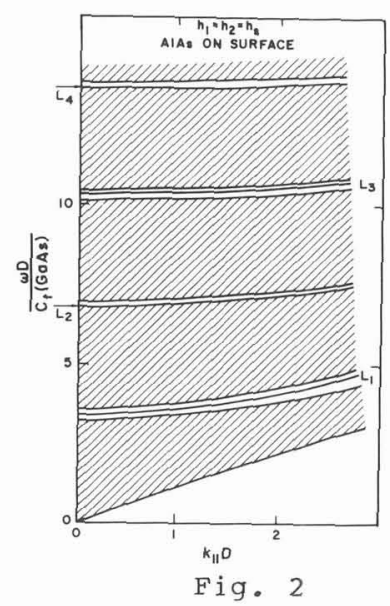

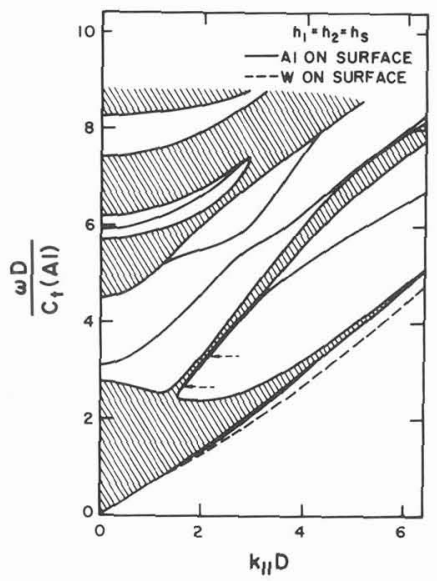

Fig. 3

different parameters which give rise to large gaps between the bulk bands). Let us stress that the surface modes are very dependent on the nature of the film at the surface and on its thickness, which may be different from that of the corresponding film in the bulk.

Finally, for shear horizontal waves, we point out the calculation of the Green's function [10] which makes possible the analysis of Brillouin scattering from such waves, for example.

This calculation can easily be extended to hexagonal crystals with (0001) interfaces, where the shear-sagittal decoupling remains valid, and also numerically to cubic crystals. Moreover, a similar formal treatment can be applied to a liquid SL - following a theory of liquid 
surfaces and interfaces[13] - taking into account the interface or surface tensions of the liquids and gravitation. These effects lead to new bands with respect to the solid case.

Finally, we mention our interest in the surface properties of a SL cut perpendicular to the laminations.

\section{Atomic Model}

Elasticity theory could fail to be valid if the films in the SL are composed of just a few atomic layers. We investigated [12] a model of a superlattice made from simple cubic crystals with interactions between nearest neighbors such that the three phonon branches are decoupled (Montroll-Potts model). The interfaces between the films are (001) planes. For this model, we were able to obtain the Green's function of an infinite or a semi-infinite sL analytically, from a knowledge of the bulk Green's function for an infinite crystal and through the following steps: (i) cut an infinite crystal along two (001) surfaces to make a thin film, (ii) link together succesive alternate films to obtain an infinite SL; (iii) cut this SL into two semi-infinite ones. The Green's function in each step results from that of the preceding step by making use of the Dyson equation. The eigenmodes are poles of the Green's function. Figure 4 illustrates the bulk bands and surface modes when each film is

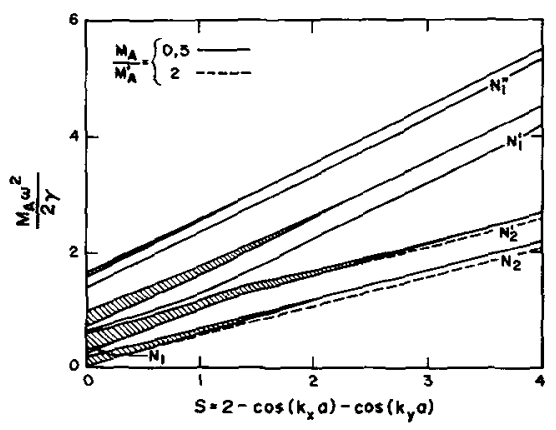

Fig. 4 two atomic layers thick, the force constants $\gamma$ are identical everywhere, and the mass ratio between the two crystals is $2: 1$.

Finally, it has been shown [9] that for films thicker than five atomic layers, the few first bands become very close to those obtained by elasticity theory.

This theory can also be applied to other vibrational models and even to the study of electronic or magnetic properties of a SL. An extension to phonons in SL formed out of two different

diatomic slabs is under study. Let us finally point out that the knowledge of the Green's function makes possible the calculation of different vibrational properties such as local and total densities of states, mean square atomic displacements, etc.

\section{References}

[1] W. M. EWING, W. S. JARDETZKY and F. PRESS, Elastic waves in layered media (McGraw-Hill, New York 1957); L. M. BREKHOVSKIKH, Waves in layered media (Academic press, New York, 1960).

[2] A. S. BARKER JR., J. I. MERZ and A. C. GOSSARD, Phys. Rev. B17 (1978) 3181 .

[3] C. COlvard, R. MERLIN, M. V. KLEIN and A. C. GOSSARD, Phys. Rev. Lett. 45 (1980) 298.

[4] J. SAPRIEL, J. C. MICHEL, J. C. TOLEDANO, R. VACHER, J. KERVAREC and $A$. REGRENY, Phys. Rev. (to appear).

[5] See in this conference, M. V. KLEIN; ibid B. JUSSERAND et al. 
[6] A. KUENY, M. GRIMSDITCH, K. MIYANO, I. BANERJEE, C. FALCO and I. SCHULLER, Phys. Rev. Lett 48 (1982) 166.

[7] B. A. AULD, G. S. BEAUPRE and G. HERRMANN, Elec. Lett. 13 (1977) 525; B. A. AUJL in Modern problems in elastic wave propagation, ed. J. MIKLOWITZ and JAN D. ACHENBACH (John Wiley and Sons, Inc., New York, 1978) p. 459.

[8] A. KUENY and M. GRIMSDITCH, Phys. Rev. B26 (1982) 4699.

[9] J. SAPRIEL, B. DJAFARI-ROUHANI and L. DOBRZYNSKI, surface Sci. 126 (1983) 197.

[10] R. E. CAMLEY, B. DJAFARI-ROUHANI, L, DOBRZYNSKI and A. A. MARADUDIN, Phys. Rev. B 27, (1983) 7318.

[11] B. DJAFARI-ROUHANI, L. DOBRZYNSKI, O. HARDOUIN DUPARC, R. E. CAMLEY and A. A. MARADUDIN, Phys. Rev. B (to appear).

[12] B. DJAEARI-ROUHANI, L. DOBRZYNSKI and O. HARDOUIN DUPARC, J. Elect. Spectr. and Rel. Phenomena 30 (1983)119, and to be published.

[13] B. DJAFARI-ROUHANI, Thesis (1978); B. DJAFARI-ROUHANI and L. DOBRZYNSKI, J. de Physique 43 (1982) 523 . 